\title{
Ultrastructure protection and attenuation of lipid peroxidation after blockade of presynaptic release of glutamate by lamotrigine in experimental spinal cord injury
}

\author{
Laboratory investigation
}

\author{
Kadir Tufan, M.D., ${ }^{1}$ Namik Oztanir, M.D., ${ }^{1}$ Ebru Ofluoglu, Ph.D., ${ }^{2}$ \\ Candan Ozogul, M.D. ${ }^{3}$ Nuket Uzum, M.D., ${ }^{4}$ Ayse Dursun, M.D., ${ }^{4}$ \\ Hatice Pasaoglu, M.D., ${ }^{2}$ and Aydin Pasaoglu, M.D. ${ }^{1}$ \\ Departments of ${ }^{1}$ Neurosurgery, ${ }^{2}$ Biochemistry, ${ }^{3}$ Histology and Embryology, and ${ }^{4}$ Pathology, \\ Gazi University Medical School, Ankara, Turkey
}

\begin{abstract}
Object. Lamotrigine is an antiepileptic drug that inhibits presynaptic voltage-gated sodium channels and reduces the presynaptic release of glutamate in pathological states. Neuroprotective effects of this drug have already been demonstrated in cerebral ischemia models. The aim of the present study was to determine the effects of presynaptic glutamate release inhibition on experimental spinal cord injury (SCI).

Methods. A total of 66 adult Wistar rats were randomly allocated into 6 groups. Group I was the control group used to obtain normal blood samples and spinal cord specimens. Spinal cord injury was introduced by using the extradural clip compression technique, but no medication was given to Group II (trauma group) rats. Group III was treated with vehicle, and the same amount of dimethyl sulfoxide used in treatment groups was administered to these rats. A dose of $50 \mathrm{mg} / \mathrm{kg}$ lamotrigine was administered intraperitoneally to Group IV (pretreatment), Group V (peritreatment), and Group VI (posttreatment) rats 30 minutes before, during, and 30 minutes after SCI, respectively. Oxidative stress parameters and transmission electron microscopic findings were examined.

Results. Blockade of presynaptic release of glutamate by lamotrigine treatment yielded protective effects on the spinal cord ultrastructure even when administered after the SCI, but it prevented oxidative stress only when it was administered before or during the SCI.

Conclusions. Currently, no available agent has been identified, that can block all the glutamate receptors at the same time. To prevent excitotoxicity in SCI, inhibiting glutamate release from the presynaptic buttons instead of blocking the postsynaptic glutamate receptors seems to be a more rational approach. Further research, such as neurobehavioral assessment, is warranted to demonstrate the probable neuroprotective effects of presynaptic glutamate release inhibition in SCI. (DOI: 10.3171/FOC.2008.25.11.E6)
\end{abstract}

\section{KeY WORDS - electron microscopy - experimental spinal cord injury • lamotrigine - lipid peroxidation $\bullet$ rat $\bullet$ spinal cord ultrastructure}

A CCUMULATION of high levels of intracellular $\mathrm{Ca}^{++}$ and $\mathrm{Na}^{+}$due to glutamate receptor activation soon after SCI results in neuronal death. ${ }^{12,17}$ This mechanism is called "excitatory amino acid toxicity" or "excitotoxicity" in short. Whereas intracellular $\mathrm{Na}^{+}$accumulation produces cytotoxic edema, $\mathrm{Ca}^{++}$accumulation causes free radical production and lipid peroxidation..$^{1,4,11}$ Because all of these glutamate-mediated pathophysiolog-

\footnotetext{
Abbreviations used in this paper: AMPA $=\alpha$-amino-3-hydroxy5-methyl-4-isoxazole propionic acid; DMSO = dimethyl sulfoxide; $\mathrm{GPX}=$ glutathione peroxidase; $\mathrm{Hb}=$ hemoglobin; $\mathrm{KA}=$ kainate; MDA = malonyl dialdehyde $;$ mGluR $=$ metabotropic glutamate receptor; $\mathrm{NBQX}=$ 2,3-dihydro-6-nitro-7-sulfamoyl-benzo(f)quinoxaline; $\mathrm{NMDA}=N$-methyl-D-aspartate; $\mathrm{SCI}=$ spinal cord injury; SOD $=$ superoxide dismutase .
}

ical mechanisms are keystones of secondary SCI, several therapeutic investigations focused on excitotoxicity and revealed beneficial results on SCI. ${ }^{1,2,4,11,14,22}$ There are no agents available that can block all the glutamate receptors at the same time. To prevent excitotoxicity in SCI, inhibiting glutamate release from the presynaptic buttons rather than blocking the postsynaptic glutamate receptors seems to be a more rational method.

Lamotrigine is an antiepileptic drug that inhibits presynaptic sodium channels and reduces the presynaptic release of glutamate, especially in pathological states in vitro., ${ }^{710,21}$ Lamotrigine has the ability to penetrate the blood-brain barrier, it is free from the cognitive adverse effects of glutamate receptor antagonists, and it also has a favorable pharmacokinetic profile. ${ }^{7,21}$ The neuroprotective effects of presynaptic glutamate release inhibitors 
were proved in several experimental focal or global cerebral ischemia models. $3,10,18,21,22$

The aim of the present study was to determine the effects of presynaptic glutamate release inhibition on SCI by evaluating oxidative stress parameters and the ultrastructural integrity of the spinal cord by the use of electron microscopy.

\section{Methods}

\section{Animal Preparation}

A total of 66 adult female Wistar rats weighing between 250 and $300 \mathrm{~g}$ each were used for this study. Prior to surgery, animals were randomly assigned to one of 6 groups, housed 5 to 6 rats per cage, exposed to a 12-hour light/dark cycle, and given free access to food and water. The Animal Ethics and Research Committee of Gazi University approved all protocols.

\section{Surgical Procedure}

The surgical procedure was performed after general anesthesia was induced by $50 \mathrm{mg} / \mathrm{kg}$ intramuscular xylazine (Rompun, Bayer). Using the prominent spinous process of the T-2 vertebra as the surgical landmark, T3-7 laminectomies were performed through a dorsal incision with the rat placed prone, and an 1-cm-long dural segment was exposed. We used the extradural clip compression model described by Rivlin and Tator ${ }^{19}$ to produce experimental SCI. An aneurysm clip (Yaşargil, catalog No. 65.250; Peter Lazic) was applied extradurally at a closing force of $90 \mathrm{~g}$ for 60 seconds.

\section{Drugs Used in the Experiment}

Lamotrigine (3,5-diamino-6-[2,3-dichlorophenyl]1,2,4-triazine) was a gift from GlaxoSmithKline Foundation. Pure lamotrigine is insoluble in water; thus it was dissolved in DMSO for a final concentration of $30 \mathrm{mg} / \mathrm{ml}$. The same amount of DMSO used for treatment groups was also administered to the vehicle group to determine the effects of this solvent on the experimental animals. The solutions were administered to treatment groups by slow intraperitoneal injection.

\section{Experimental Groups}

The animals were randomly allocated into 6 groups of 11 rats each, as follows. Group I (control group): laminectomies were performed, but medication was not administered, nor was SCI induced in the rats. The spinal cord and blood samples were used to obtain the basal values. Group II (trauma group): SCI was performed, but no medication was administered to the rats. Group III (vehicle group): an equal amount of DMSO to that used as solvent for treatment groups was administered to the rats. Group IV (pretreatment group): $50 \mathrm{mg} / \mathrm{kg}$ lamotrigine was administered intraperitoneally to the rats 30 minutes before experimental SCI. Group V (peritreatment group): $50 \mathrm{mg} / \mathrm{kg}$ lamotrigine was administered intraperitoneally to the rats simultaneously with experimental SCI. Group VI (posttreatment group): $50 \mathrm{mg} / \mathrm{kg}$ lamotrigine was ad- ministered intraperitoneally to the rats 30 minutes after experimental SCI.

\section{Sample Preparation}

The oxidative stress parameters reach peak concentration over 1-5 hours after SCI and decrease gradually. Seven rats in each group were killed with a lethal dose of intraperitoneal pentobarbital sodium 2 hours post injury for the biochemical analysis. The remaining 4 rats in each group were killed in the same fashion 24 hours postinjury, and the spinal cord tissue samples were collected for pathological analysis. One centimeter of the injured spinal cord segment was removed, weighed, and immediately frozen and stored at $-70^{\circ} \mathrm{C}$ until analysis for tissue MDA was performed. Subsequently, 2-ml blood samples were drawn into tubes containing heparin; these were separated into $0.5-\mathrm{ml}$ whole blood samples for GPX analysis, washed erythrocyte samples for SOD analysis, and plasma samples for MDA analysis.

\section{Biochemical Analysis}

Tissue MDA Analysis. The relative levels of tissue MDA, an indicator of lipid peroxidation, were measured using a thiobarbituric acid assay as described by Ohkawa et al. ${ }^{15}$ The levels of tissue MDA were expressed as "nmol/g wet tissue."

Plasma MDA Analysis. Plasma lipid peroxide levels were measured colorimetrically by the thiobarbituric acid assay described by Yoshioka et al., ${ }^{23}$ and expressed as "nmol/ml."

Erythrocyte SOD Activity Analysis. Addition of SOD accelerates the dismutation of the toxic superoxide radicals $\left(\mathrm{O}_{2}^{-}\right)$produced during the oxidative energy process into $\mathrm{H}_{2} \mathrm{O}_{2}$ and molecular $\mathrm{O}_{2}$. The SOD levels are decreased by excessive oxidative stress. We measured the erythrocyte SOD activity with the aid of a RANSOD Kit (SD125, Randox). The Hb levels were measured using the Drabkin method, 5 and results were expressed as "U/g Hb."

Glutathione Peroxidase Activity Analysis. The GPX activity of blood was measured according to the method described by Paglia and Valentine, ${ }^{16}$ by using a RANSEL Kit (RS504, Randox). The Hb levels were measured using the Drabkin method, and results were expressed as " $\mathrm{U} / \mathrm{g}$ $\mathrm{Hb}$ ". 5

Pathological Analysis. The 4 spinal cord samples used for pathological analysis were collected 24 hours after experimental injury, because the expected histopathological changes become evident over 24 hours. A $1-\mathrm{cm}$ spinal cord segment was removed from each injury site, and divided from the epicenter of the contusion level.

\section{Transmission Electron Microscopy Analysis}

The tissues used for transmission electron microcopy were kept in $2.5 \%$ glutaraldehyde and $2 \%$ paraformaldehyde solutions for 24 hours, postfixed with phosphatebuffered $2 \% \mathrm{OsO}_{4}$ for 1 hour, and dehydrated in a graded series of alcohols. The samples were embedded in aralde- 


\section{Effects of lamotrigine on experimental spinal cord injury}

TABLE 1: Grading system for quantitative evaluation of ultrastructural findings in rats with $\mathrm{SCl}^{*}$

\begin{tabular}{lc}
\hline \multicolumn{1}{c}{ Category } & Score \\
\hline axonal myelin & \\
normal myelin layers & 0 \\
vesiculated myelin & 1 \\
cracked myelin layers & 2 \\
honeycombed \& extruded vesicles & 3 \\
general axonal score & \\
normal & 0 \\
light edema & 1 \\
mild edema & 2 \\
severe edema \& loss of structure & 3 \\
intracytoplasmic edema & \\
absent & 0 \\
light & 1 \\
mild & 2 \\
severe (cell membrane defect) & 3 \\
nucleus & \\
normal & \\
clumping & \\
sparse chromatin & \\
severe damage & \\
mitochondrion & \\
normal & \\
light edema & \\
mild edema & \\
severe edema \& loss of structure & 3 \\
\hline
\end{tabular}

* Twenty neurons/sample were evaluated for intracellular edema and nucleus, 20 axons/sample were evaluated for axonal chang$\mathrm{es}$, and 20 mitochondria/sample were evaluated for mitochondrial changes.

hyde, then 1- to 2-micron semithin sections were obtained with an ultratome (Reichert Supernova) and stained with toluidine blue. Semithin sections were evaluated under a light microscope (Olympus $\mathrm{CH}-2$ ), and characteristic areas were chosen as sites for thin sections. The thin sections were obtained with the same ultratome, uranyl acetate and lead citrate were added as contrast agents, and sections were evaluated with the transmission electron microscope (EM 900, Carl Zeiss, Inc.).

An ultrastructural scoring system described by Kaptanoglu and colleagues ${ }^{8,9}$ was used for quantitative evaluation of the spinal cord samples (Table 1). Twenty neurons/sample were evaluated for intracellular edema and nucleus; 20 axons/sample were evaluated for axonal changes; and 20 mitochondria/sample were evaluated for mitochondrial changes.

\section{Statistical Analysis}

All the data collected throughout the experiment were analyzed using SPSS for Windows version 10.0 statistical software. Statistical analysis of each parameter was performed using one-way analysis of variance. The Tukey test was applied for intergroup comparisons and a

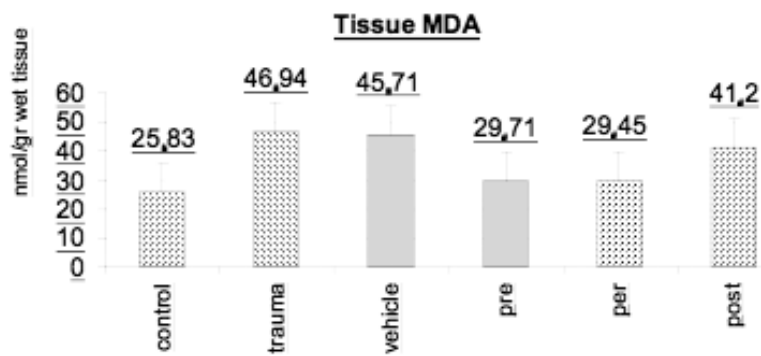

FIG. 1. Bar graph showing distribution of mean tissue MDA levels in rats according to experimental groups.

probability value less than 0.05 was accepted as statistically significant.

\section{Results}

Tissue MDA Levels

The mean tissue MDA levels were $25.83 \mathrm{nmol} / \mathrm{g}$ for the control group, $46.94 \mathrm{nmol} / \mathrm{g}$ for the trauma group, $45.71 \mathrm{nmol} / \mathrm{g}$ for the vehicle group, $29.71 \mathrm{nmol} / \mathrm{g}$ for the pretreatment group, $29.45 \mathrm{nmol} / \mathrm{g}$ for the peritreatment group, and $41.2 \mathrm{nmol} / \mathrm{g}$ for the posttreatment group. There was a statistically significant difference between control and trauma groups $(\mathrm{p}<0.05)$. The vehicle group did not show a difference from the trauma group $(\mathrm{p}>0.05)$. This result showed that the solvent did not change the oxidative stress parameters at the dose used. There were statistically significant differences between the trauma group and pre- and peritreatment groups $(\mathrm{p}<0.05)$. Nevertheless, there was no statistically significant difference between the trauma and posttreatment groups (p >0.05) (Fig. 1).

\section{Plasma MDA Levels}

The mean plasma MDA levels were $10.16 \mathrm{nmol} /$ $\mathrm{ml}$ for the control group, $21.05 \mathrm{nmol} / \mathrm{ml}$ for the trauma group, $20.57 \mathrm{nmol} / \mathrm{ml}$ for the vehicle group, $10.96 \mathrm{nmol} /$ $\mathrm{ml}$ for the pretreatment group, $10.75 \mathrm{nmol} / \mathrm{ml}$ for the peritreatment group, and $10.59 \mathrm{nmol} / \mathrm{ml}$ for the posttreatment group. There was a statistically significant difference between the control and trauma groups $(\mathrm{p}<0.05)$. The vehicle group did not differ significantly from the trauma group ( $\mathrm{p}>0.05)$. Plasma MDA levels in the trauma group were significantly higher than in pre-, peri-, and posttreatment groups $(\mathrm{p}<0.05)$. There were no statistically significant differences between the treatment groups $(\mathrm{p}>$ 0.05) (Fig. 2).

\section{Erythrocyte SOD Activity}

The mean plasma SOD activity levels were $4083 \mathrm{U} / \mathrm{g}$ $\mathrm{Hb}$ for the control group, $1874 \mathrm{U} / \mathrm{g} \mathrm{Hb}$ for the trauma group, $1793 \mathrm{U} / \mathrm{g} \mathrm{Hb}$ for the vehicle group, $3830 \mathrm{U} / \mathrm{g} \mathrm{Hb}$ for the pretreatment group, $3574 \mathrm{U} / \mathrm{g} \mathrm{Hb}$ for the peritreatment group, and $2713 \mathrm{U} / \mathrm{g} \mathrm{Hb}$ for the posttreatment group. There was a statistically significant difference between the control and trauma groups $(\mathrm{p}<0.05)$. The difference between the vehicle and trauma groups was not significant $(\mathrm{p}>0.05)$. Erythrocyte SOD activities in pre- and 


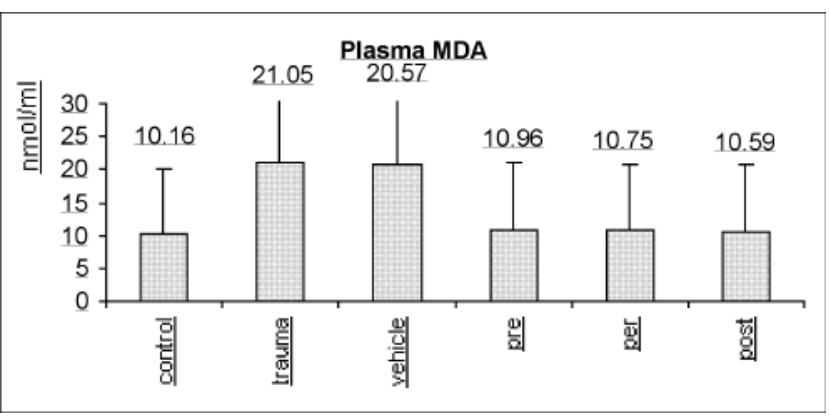

FIG. 2. Bar graph showing distribution of mean blood MDA levels in rats according to experimental groups.

peritreatment groups were significantly higher than the trauma group $(\mathrm{p}<0.05)$, but there was no statistically significant difference between the trauma group and the posttreatment group ( $\mathrm{p}>0.05)$ (Fig. 3).

\section{Plasma GPX Activity}

The mean plasma GPX activity levels were $17.59 \mathrm{U} / \mathrm{g}$ $\mathrm{Hb}$ for the control group, $12.51 \mathrm{U} / \mathrm{g} \mathrm{Hb}$ for the trauma group, $11.43 \mathrm{U} / \mathrm{g} \mathrm{Hb}$ for the vehicle group, $16.66 \mathrm{U} / \mathrm{g} \mathrm{Hb}$ for the pretreatment group, $17.56 \mathrm{U} / \mathrm{g} \mathrm{Hb}$ for the peritreatment group, and $14.13 \mathrm{U} / \mathrm{g} \mathrm{Hb}$ for the posttreatment group. A statistically significant difference was found between the control and trauma groups $(\mathrm{p}<0.05)$. The vehicle group did not show a difference from the trauma group ( $\mathrm{p}>0.05)$. The GPX activities in the pretreatment group were significantly higher than in the trauma group $(\mathrm{p}<0.05)$, but we did not find statistically significant differences between the trauma group and the peri- and posttreatment groups ( $\mathrm{p}>0.05)$ (Fig. 4).

Lamotrigine $(50 \mathrm{mg} / \mathrm{kg})$ treatment appeared to be neuroprotective from oxidative stress when it was applied before or during, but not after the SCI.

\section{Electron Microscopic Evaluation Results}

The control group demonstrated normal spinal cord ultrastructure, whereas the trauma group showed significant damage to the ultrastructure. Severe intracytoplasmic and mitochondrial edema, damage to the neuronal nuclei, cracked or completely destroyed myelin layers, and few axons in the white matter were seen in the trauma group. The vehicle group demonstrated similar findings to the trauma group. The ultrastructure of the spinal cord was significant-

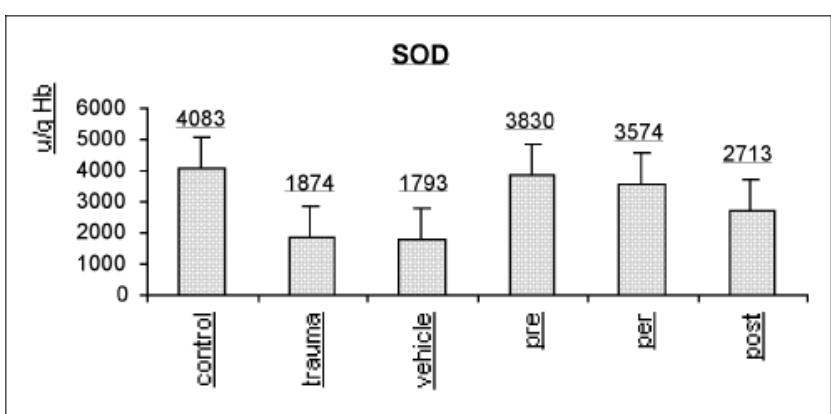

FIG. 3. Bar graph showing distribution of mean erythrocyte SOD activity in rats according to experimental groups.

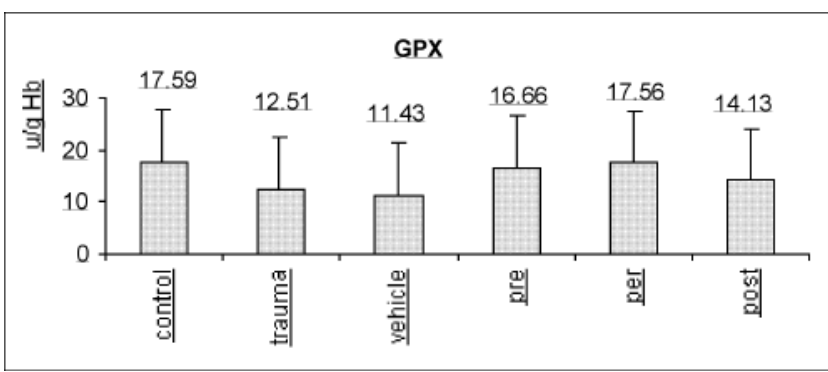

FIG. 4. Bar graph showing distribution of mean GPX levels in rats according to experimental groups.

ly spared in all treatment groups. Mostly, preserved axons, intact myelin layers, normal nuclei, and mitochondria were seen in the treatment groups (Figs. 5 and 6).

According to the ultrastructural grading system described by Kaptanoglu and colleagues, ${ }^{8,9}$ there were statistically significant differences between the control group and the trauma and vehicle groups $(p<0.05)$. The vehicle group did not show a significant difference from the trauma group $(\mathrm{p}>0.05)$. The pre-, peri-, and posttreatment groups showed significant ultrastructural protection compared with the trauma group $(\mathrm{p}<0.05)$. There were no statistically significant differences between the treatment groups $(\mathrm{p}>0.05)$.

\section{Discussion}

Following SCI, glutamate concentration reaches toxic levels. ${ }^{12,17}$ Liu et al. reported that SCI causes a dramatic and long-lasting increase of excitatory amino acids, probably high enough to kill neurons. Glutamate shows its excitotoxic effects through well-known glutamate receptors such as NMDA, AMPA, KA, and mGluRs. , $2,4,11,14,22^{2}$

Studies have shown that glutamate exacerbates different processes of neuronal injury. First, it promotes an intracellular $\mathrm{Ca}^{++}$increase, which may activate proteolysis and lipid peroxidation, damaging the cellular membrane and resulting in neuronal death. Second, glutamate mediates significant ion shifts that cause cellular edema. ${ }^{1,2,4,11,12,14,17,22}$

It becomes evident from these earlier studies that the

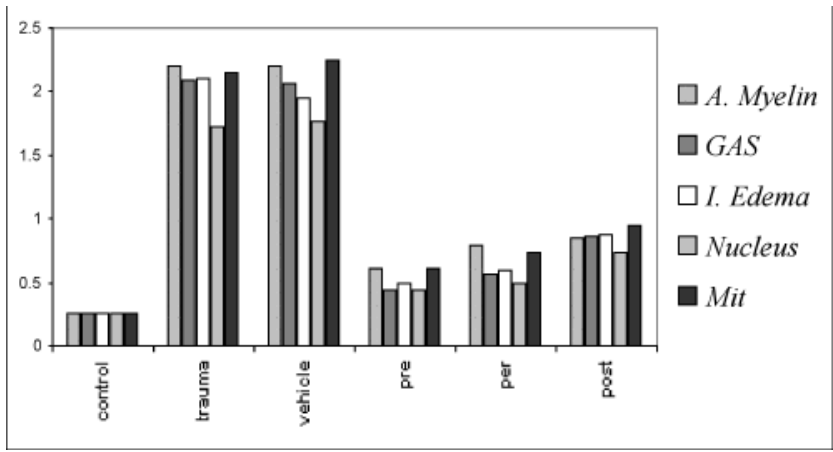

FIG. 5. Bar graph showing ultrastructural scores (y axis) of spinal cord according to experimental groups; scores were determined using a grading system for quantitative evaluation of ultrastructural findings. A. = axonal; GAS = general axonal score; I. = intracytoplasmic; Mit = mitochondria. 
Effects of lamotrigine on experimental spinal cord injury

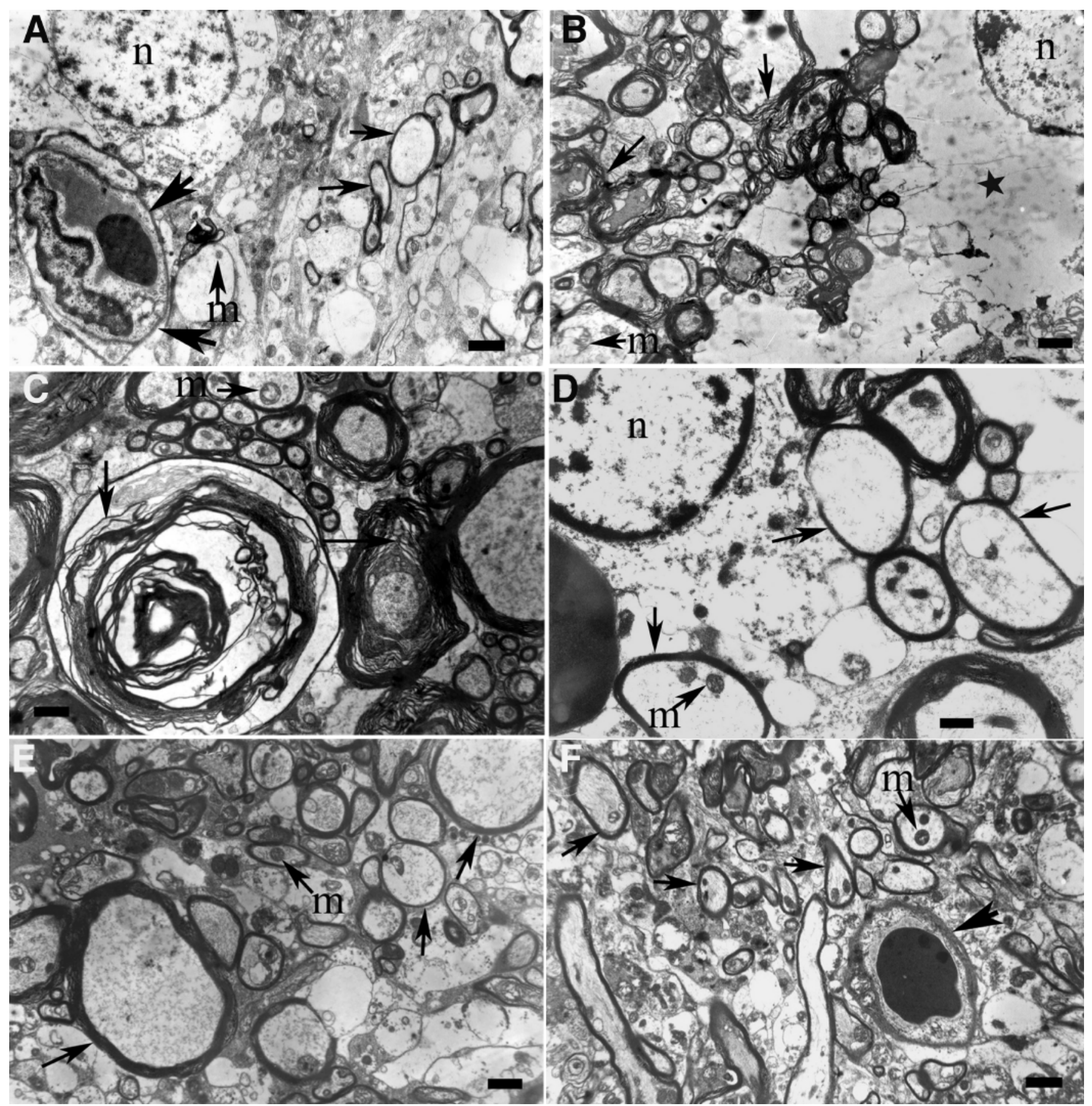

Fig. 6. Electron micrographs of tissue obtained in the 6 groups of rats. A: Tissue from a rat in the control group, demonstrating normal appearance of nucleus (n), mitochondria (m), myelin sheath (thin arrows), and vessel wall (thick arrows). B: Tissue obtained in the trauma group, showing sparse chromatin of nucleus, severe edema of mitochondria, cracked myelin layers (arrows), and severe intracytoplasmic edema (star). C: Tissue obtained in the vehicle group, demonstrating cracked myelin layers (arrows) and edema of mitochondria. The electron microscopy findings in the vehicle group were generally similar to those in the trauma group. D: Tissue obtained in the pretreatment group, demonstrating generally normal or mildly edematous mitochondria, euchromatic nucleus, the normal myelin layers in thin myelinated fibers (arrows), but some vesicles are seen in thick myelinated axons. E: Tissue obtained in the peritreatment group, showing generally near-normal myelin layers (arrows) and mitochondria. F: Tissue obtained in the posttreatment group, demonstrating evidence of normal or mildly edematous mitochondria, generally normal myelin layers (thin arrows), and normal vessel wall (thick arrows). Bars $=4 \mu \mathrm{m}$.

glutamate-activated process is the keystone in traumatic neuronal injury, and that pharmacological interventions at different steps of the excitotoxic cascade may help at- tenuate traumatic neuronal death. That is why so many glutamate receptor antagonists were used in experimental SCI. ${ }^{1,2,4,11,14,22}$ 
Overstimulation of NMDA receptors by a high concentration of glutamate causes $\mathrm{Ca}^{++}$influx and mediates neuronal $\mathrm{Ca}^{++}$-related cytotoxicity. Beneficial effects of some NMDA receptor antagonists such as MK-801 were reported in different central nervous system trauma and ischemia models. ${ }^{1,4,11}$ However, adverse effects such as cognitive dysfunction and the hallucinogenic properties of MK-801 restricted its clinical use. ${ }^{13}$

It is now clear that other ionotropic receptors, such as AMPA and KA, are directly permeable to $\mathrm{Ca}^{++}$in addition to their $\mathrm{Na}^{+}$permeability. ${ }^{1,6,13,22}$ Because they can be important sources of $\mathrm{Ca}^{++}$influx in neurons, some AMPA/KA receptor blockers such as NBQX were used in experimental SCI models, and beneficial effects were reported. ${ }^{6,13}$ Nephrotoxic adverse effects of NBQX limited its clinical usage.

The other glutamate receptors are nonionotropic receptors, known as mGluRs. Among these receptors, Group I mGluR activation initiates a number of intracellular pathways that lead to further transmitter release. ${ }^{2,14}$ Group II and III mGluRs regulate neurotransmitters in pathological states such as trauma and ischemia., ${ }^{2,14}$ The effects of mGluR antagonists on experimental SCI were investigated in some recent studies. Results suggested that mGluRs play important roles in excitotoxicity after spinal trauma and development of chronic central pain syndromes. ${ }^{2,14}$

All these data demonstrated that glutamate shows its excitotoxic effect through several different receptor types. Currently, no available agent has been identified that can block all the glutamate receptors at the same time. To prevent excitotoxicity in SCI, inhibiting glutamate release from the presynaptic buttons instead of blocking the postsynaptic glutamate receptors seems to be a more rational method.

Lamotrigine is an antiepileptic drug that inhibits presynaptic glutamate release through voltage-gated $\mathrm{Na}^{+}$ channel blockage. Neuroprotective effects of lamotrigine have been reported in several experimental models. Lamotrigine reduces infarct volume and lipid peroxidation and improves neurological outcome after focal and global cerebral ischemia. 3,18,20,21 The most important neuroprotective action of lamotrigine is inhibition of overstimulation of glutamate receptors by decreasing presynaptic glutamate release in pathological states. Moreover, cell culture studies demonstrated that lamotrigine has direct antagonistic effects on Ca channels in addition to $\mathrm{Na}^{+}$channels. ${ }^{10,21}$ Because lamotrigine inhibits $\mathrm{Na}^{+}$influx through voltage-gated $\mathrm{Na}^{+}$channel blockage, it may diminish the accumulation of intracellular $\mathrm{Na}^{+}$and the movement of water into the neurons. Also it may maintain more stable and more negative membrane potentials. ${ }^{10,21}$

The aim of this study was to determine the effects of inhibition of presynaptic glutamate release by lamotrigine on experimental SCI. We administered $50 \mathrm{mg} /$ $\mathrm{kg}$ lamotrigine intraperitoneally to the treatment groups 30 minutes before, 30 minutes after, and simultaneously with the SCI. Neuroprotective effects of $50 \mathrm{mg} / \mathrm{kg}$ lamotrigine have been shown in previous studies, with no significant adverse effects reported. Rataud et al. ${ }^{18}$ re- ported that animals treated with $50 \mathrm{mg} / \mathrm{kg}$ but not $25 \mathrm{mg} /$ $\mathrm{kg}$ lamotrigine showed significant reduction in the size of cortex infarction in focal cerebral ischemia. In the study by Bacher and Zornow, ${ }^{3}$ the authors reported that, in a transient global cerebral ischemia model, $50 \mathrm{mg} / \mathrm{kg}$ lamotrigine was more effective in inhibiting the glutamate accumulation than $20 \mathrm{mg} / \mathrm{kg}$ lamotrigine.

Because pure lamotrigine is insoluble in water, we dissolved it in DMSO, with a final concentration of 30 $\mathrm{mg}$ lamotrigine/1 $\mathrm{ml}$ DMSO. Some beneficial effects of DMSO on SCI have been reported in previous studies. ${ }^{24}$ Nevertheless, the dose of DMSO used as the solvent in the present study was approximately one-tenth of its therapeutic dose. ${ }^{24}$ We administered the same amount of DMSO to the vehicle group to evaluate the potential effects of the solvent in our study. There were no statistically significant differences in any oxidative stress parameters and results of histopathological analysis between the trauma and vehicle groups.

In our study, the effects of presynaptic glutamate release inhibition by lamotrigine on oxidative stress were evaluated by assessing plasma and tissue MDA, SOD, and GPX levels. The results suggested that lamotrigine diminishes the level of oxidative stress parameters in SCI, but only when it was applied before or simultaneously with the injury. However, beneficial effects on oxidative stress were not observed when lamotrigine was applied 30 minutes after the SCI. Because glutamate reaches a peak level within 15-30 minutes after SCI, the treatment administered after that period may be ineffective in preventing excitotoxic events. ${ }^{12,17}$

Histopathological changes in the present study were evaluated by electron microscopic analysis. Presynaptic glutamate release inhibition was highly protective to the spinal cord ultrastructure after SCI in pre-, peri-, and posttreatment groups.

Although presynaptic glutamate release inhibition by lamotrigine treatment 30 minutes after SCI was not effective on oxidative stress parameters (except blood MDA levels), highly protective effects have been shown on the spinal cord ultrastructure. In our opinion, these effects can be related to different neuroprotective mechanisms of lamotrigine such as its membrane stabilizing and antiedema effects, in addition to its well-known role as an antiexcitotoxic. Limitations of this work are the brief posttreatment period and absence of neurobehavioral assessments.

\section{Conclusions}

By exhibiting protective effects on the spinal cord ultrastructure even after SCI, presynaptic glutamate release inhibitors such as lamotrigine are promising drugs in the treatment of these injuries. To the best of our knowledge, this is the first study on the neuroprotective effects of presynaptic glutamate release. Further research, such as neurobehavioral assessment, is warranted to explore whether the beneficial effects of presynaptic glutamate release inhibition on the spinal cord ultrastructure will have any beneficial functional implications in the long term. 


\section{Effects of lamotrigine on experimental spinal cord injury}

\section{Disclaimer}

The authors report no conflict of interest concerning the materials or methods used in this study or the findings specified in this paper.

\section{References}

1. Agrawal SK, Fehlings MG: Role of NMDA and non-NMDA ionotropic glutamate receptors in traumatic spinal cord axonal injury. J Neurosci 17:1055-1063, 1997

2. Agrawal SK, Theriault E, Fehlings MG: Role of group I metabotropic glutamate receptors in traumatic spinal cord white matter injury. J Neurotrauma 15:929-941, 1998

3. Bacher A, Zornow MH: Lamotrigine inhibits extracellular glutamate accumulation during transient global cerebral ischemia in rabbits. Anesthesiology 86:459-463, 1997

4. Faden AI, Lemke M, Simon RP, Noble LJ: N-methyl-D-aspartate antagonist MK801 improves outcome following traumatic spinal cord injury in rats: behavioral, anatomic, and neurochemical studies. J Neurotrauma 5:33-45, 1988

5. Fairbanks FB, Klee GG: Biochemical aspects of haematology in Burtis CA, Ashwood ER (eds): Tietz Textbook Of Clinical Chemistry, ed 2. Philadelphia, WB Saunders Company: 1994, pp 1974-2072

6. Hollmann M, Hartley M, Heinemann S: Ca2+ permeability of KA-AMPA-gated glutamate receptor channels depends on subunit composition. Science 252:851-853, 1991

7. Hurley SC: Lamotrigine update and its use in mood disorders. Ann Pharmacother 36:860-873, 2002

8. Kaptanoglu E, Palaoglu S, Surucu HS, Hayran M, Beskanonakli E: Ultrastructural scoring of graded acute spinal cord injury in the rat. J Neurosurg 97 (1 Suppl):49-56, 2002

9. Kaptanoglu E, Solaroglu I, Okutan O, Surucu HS, Akbiyik F, Beskonakli E: Erythropoietin exerts neuroprotection after acute spinal cord injury in rats: effect on lipid peroxidation and early ultrastructural findings. Neurosurg Rev 27:113120,2004

10. Lees G, Leach MJ: Studies on the mechanism of action of the novel anticonvulsant lamotrigine using primary neurological cultures from rat cortex. Brain Res 612:190-199, 1993

11. Li S, Tator CH: Effects of MK801 on evoked potentials, spinal cord blood flow and cord edema in acute spinal cord injury in rats. Spinal Cord 37:820-832, 1999

12. Liu D, Thangnipon W, McAdoo DJ: Excitatory amino acids rise to toxic levels upon impact injury to the rat spinal cord. Brain Res 547:344-348, 1991
13. Low SJ, Roland CL: Review of NMDA antagonist-induced neurotoxicity and implications for clinical development. Int J Clin Pharmacol Ther 42:1-14, 2004

14. Mills CD, Johnson KM, Hulsebosch CE: Role of Group II and Group III metabotropic glutamate receptors in spinal cord injury. Exp Neurol 173:153-167, 2002

15. Ohkawa H, Ohishi N, Yagi K: Assay for lipid peroxides in animal tissues by thiobarbituric acid reaction. Anal Biochem 95:351-358, 1979

16. Paglia DE, Valentine WN: Studies on quantitative and qualitativ characterization of erythrocyte glutathione peroxidase. J Lab Clin Med 70:158-168, 1967

17. Panter SS, Yum SW, Faden AI: Alteration in extracellular amino acids after traumatic spinal cord injury. Ann Neurol 27:96-99, 1990

18. Rataud J, Debarnot F, Mary V, Pratt J, Stutzmann JM: Comparative study of voltage-sensitive sodium channel blockers in focal ischaemia and electric convulsions in rodents. Neurosci Lett 172:19-23, 1994

19. Rivlin AS, Tator CH: Effect of duration of acute spinal cord compression in a new acute cord injury model in the rat. Surg Neurol 10:38-43, 1978

20. Smith SE, Meldrum BS: Cerebroprotective effect of lamotrigine after focal ischemia in rats. Stroke 26:117-121, 1995

21. Stefani A, Spadoni F, Bernardi G: Differential inhibition by riluzole, lamotrigine, and phenytoin of sodium and calcium currents in cortical neurons: implications for neuroprotective strategies. Exp Neurol 147:115-122, 1997

22. Wrathall JR, Choiniere D, Teng YD: Dose-dependent reduction of tissue loss and functional impairment after spinal cord trauma with the AMPA/kainate antagonist NBQX. J Neurosci 14:6598-6607, 1994

23. Yoshioka T, Kawada K, Shimada T, Mori M: Lipid peroxidation in maternal and cord blood and protective mechanism against activated oxygen toxicity in the blood. Am J Obstet Gynecol 135:372-376, 1979

24. Zileli M, Ovul I, Dalbasti T: Effects of methyl prednisolone, dimethyl sulphoxide and naloxone in experimental spinal cord injuries in rats. Neurol Res 10:232-235, 1988

Manuscript submitted June 29, 2008

Accepted September 4, 2008.

Address correspondence to: Kadir Tufan, M.D., Baskent Universitesi, Adana Uygulama ve Araştırma, Merkezi, Beyin Cerrahi A.D., Yuregir, Adana, 01250 Turkey. email: tufankadir@ yahoo.com. 